\title{
Ketamine Hydrochloride for Painless Labour - An Interventional Study
}

\author{
Padmaja Abhay Havle, Rajkumar P. Patange ${ }^{2}$, Pranav Abhay Havle ${ }^{3}$, Sanket Chandrashekhar Prabhune ${ }^{4}$ \\ 1, 2, Department of Obstetrics \& Gynaecology, Krishna Institute of Medical Sciences (Deemed to Be \\ University), Karad, Maharashtra, India. ${ }^{3}$ Department of ENT, SMBT Institute of Medical Sciences and \\ Research Centre, Maharashtra, India. ${ }^{4}$ Department of Otorhinolaryngology, Krishna Institute of Medical \\ Sciences (Deemed to Be University), Karad, Maharashtra, India.
}

\section{ABSTRACT}

\section{BACKGROUND}

Ketamine hydrochloride is a short acting anaesthetic used in obstetrics for painless vaginal delivery. Besides being an anaesthetic, it has an oxytocic action too. Analgesic action of Ketamine hydrochloride at sub anaesthetic dose is well known. Its simultaneous actions on uterus and the fetus in cases of full-term pregnancy in active labour in addition to painless labour were evaluated at rural tertiary care teaching hospital. We wanted to study the effects of a slow intravenous sub anaesthetic (low) dose ketamine hydrochloride as an agent for painless labour, and its effect on progress of labour and Apgar score of new-borns.

\section{METHODS}

An interventional study to find out effectiveness of low dose Ketamine hydrochloride in a slow IV drip for painless labour in cases with full term pregnancy in active labour, was conducted at tertiary care rural hospital of western Maharashtra. A total of 73 cases as per set inclusion and exclusion criteria was included in the study. Administration of low dose of Ketamine hydrochloride $(1 \mathrm{mg} / \mathrm{Kg}$ ) in a slow IV drip of $500 \mathrm{~mL}$ dextrose at 50 drops per minutes was started during active labour and continued till delivery of foetus in every case. In all cases, uterine contractions, cervical dilatation, foetal heart rate, and vital signs during infusion of the Ketamine were monitored frequently. Also, injection Midazolam $2 \mathrm{mg}$ IV was administered after delivery of foetus in every case. Magnitude of labour pains was assessed on VAS during and after labour. The emergence reactions of Ketamine hydrochloride if any were looked for and Apgar scores at 1 and 5 minutes after birth were noted in all cases.

\section{RESULTS}

Out of 80 cases enrolled, initially 7 had to be excluded as 4 and 3 of these had to be delivered by assisted forceps delivery and LSCS respectively under anaesthesia. Among the remaining 73 cases who delivered spontaneously (normal), the total duration of labour was within 6 hrs. in 8 cases, 6 - 8 hours in 48 and 8 - 10 hrs. in 17 with a mean of $7.4 \pm 1.6$ hours. Significant relief from labour pain on VAS (Visual Analogue Scale) score of zero ( $p<0.0001)$ was found in $61(83.57 \%)$ out of 73 cases. Apgar score at 1 and 5 minutes was significantly more than $7(\mathrm{p}<0.0001)$ in 69 (92 $\%)$ out of 75 newborn delivered spontaneously including 2 twin babies. The emergence reactions found within one hour of stopping of Ketamine drip were hallucinations in 6 , delirium in 2 , restlessness in 5 , drowsiness in 16 , vomiting in 5 , nausea in 3 , headache in 2 , and giddiness in 11 while rest were without any complications.

\section{CONCLUSIONS}

Low dose IV Ketamine hydrochloride was effective in 83.57 \% of cases opting for painless delivery at term as it provided relief of active labour pains without affecting the process of labour besides being easy to administer and monitor, without any significant associated maternal and fetal morbidity.

\section{KEY WORDS}

Apgar Score, Analgesics, Ketamine, Labour Pain, Pregnancy

\author{
Corresponding Author: \\ Dr. Pranav Abhay Havle, \\ Department of ENT, \\ SMBT Institute of Medical Sciences \\ and Research Centre, \\ Nandi-Hills, Dhamangaon, \\ Maharashtra, India. \\ E-mail: padmaja0909@gmail.com
}

DOI: $10.14260 /$ jemds $/ 2020 / 741$

How to Cite This Article:

Havle PA, Patange RP, Havle PA, et al. Ketamine hydrochloride for painless labour-an interventional study. J Evolution Med Dent Sci 2020;9(45):3373-3376, DOI: 10.14260/jemds/2020/741

Submission 20-08-2020,

Peer Review 28-09-2020,

Acceptance 05-10-2020,

Published 09-11-2020.

Copyright (C) 2020 Padmaja Abhay Havle et al. This is an open access article distributed under Creative Commons Attribution License [Attribution 4.0 International (CC BY 4.0)] 


\section{BACKGROUND}

More than one modality is available for painless labour. It can be accomplished by using techniques like epidural block, spinal block, combined spinal epidural block, pudendal block and general anaesthesia; however the one using ketamine hydrochloride in low dose controlled IV (Intravenous) drip is easy, safe and less morbid. The technique with epidural and spinal block have advantages like regional action, safe to fetus as it cannot reach systemically and provides good muscle relaxation. However, it requires skill of administration and is associated with possibility of trauma, CSF leak with head ache, hypotension etc. A pudendal block is capable of relieving pain in the lower vagina and perineum for up to an hour yet less harmful to fetus; however pudendal block may fail at times or may act unilaterally on perineum and having other untoward effects such as hypersensitivity and possibility of infection at the injection site. General anaesthesia has unwanted suppression of labour and fetus. Non-drug pain management such as by way of massage, deep breathing or relaxation, Kegels exercises, aromatherapy, homeopathy, acupuncture and hypnotherapy can be other techniques of pain relief but not yet been proven for labour analgesia. TENS (Transcutaneous Electric Nerve Stimulation) can be used in combination with other types of pain relief as it allows mother to remain active throughout but it is usually effective with just mild to moderate pain and there is only limited evidence that TENS reduces pain in labour and it does not seem to have any impact (either positive or negative) on other outcomes for mothers or babies and hence the possibility of associated theoretical risk. ${ }^{1}$ In recent years, epidural narcotics have been used to provide good pain relief in labour pains but this method is still subject to certain drawbacks, the most serious of which being delayed respiratory depression.

Ketamine hydrochloride is an ideal analgesic agent due to its water-soluble nature and ability to remain stable in solution with long half-life (after dilution), besides being nonirritant when administered either intramuscularly (IM) or intravenously, smooth in onset of action and undergoes rapid degradation to inactive nontoxic metabolites. Ketamine is an $\mathrm{N}$-methyl-D-aspartate receptor antagonist, with excellent analgesic property even in sub anaesthetic doses. It provides dissociative form of anaesthesia characterized by catalepsy, catatonia and more importantly analgesia and amnesia without involving loss of consciousness or state of general anaesthesia. It is readily available and is being used currently, even by non-anaesthesiologists, for providing "sedation" during minor procedures. ${ }^{2}$ Effective pain relief prevents maternal exhaustion and facilitates enhanced co-operation of mother. It also reduces stress related elevation of catecholamine and allows smooth cervical dilatation, making labour more tolerable and enjoyable experience. ${ }^{3}$ The phencyclidine derivative ketamine is widely used as intramuscular and intravenous anaesthetic agent. In contrast to other anaesthetics, ketamine has a potent analgesic property even at sub anaesthetic dose. Recent studies indicate that analgesia produced by ketamine is mediated through opiate receptors and N-methyl-D aspartate receptors. As systematically administered ketamine is unlikely to produce the respiratory depression, it seemed to offer an obvious advantage over the narcotics in which major drawback is respiratory depression. ${ }^{4}$ In this study the effectiveness of low dose ketamine hydrochloride as an agent for painless labour at full term pregnancy and its effects on uterine contractions as well as fetus was studied.

\section{METHODS}

An interventional study to find out effectiveness of low dose of ketamine hydrochloride as an agent for painless labour in slow IV drip and its effect on progress of labour and fetus was conducted at tertiary care rural hospital of Western Maharashtra. As found with other similar studies the sample size of 60 cases was considered adequate and 20 more were added for possibility of dropouts requiring assisted deliveries under anaesthesia in this study initially. Thus 80 women with full term pregnancy in active labour, willing to participate in the study and expected to deliver vaginally after pelvic assessment, irrespective of the number of gravid were included in the study. All full term cases with co morbid conditions like hypertension, heart diseases, cephalo pelvic disproportion and history of previous Lower Segment Caesarean Section (LSCS), epilepsy and psychiatric disorders were excluded from the study. Out of 80 cases enrolled initially, 7 requiring surgical assistance under additional anaesthesia like LSCS in 3 and forceps delivery in 4 cases during the study period were also excluded and study was concluded with remaining 73 cases. All enrolled cases were subjected to routine bedside obstetric assessment and investigations like vital signs, weight in kilograms, $\mathrm{Hb} \%$, urine, VDRL, blood grouping Rh typing BT, CT, HIV and HBsAg etc.

\begin{tabular}{|l|l|}
\hline $\begin{array}{l}\text { Initially } 80 \text { women with full term pregnancy in active labour } \\
\text { enrolled in the study as per set inclusion criterions }\end{array}$ \\
\hline $\begin{array}{l}\text { Number of cases } \\
\text { remained in the study } \\
\text { n=73 }\end{array}$ & $\begin{array}{l}\text { Number of cases requiring assisted delivery } \\
\text { (LSCS or forceps) under anesthesia and } \\
\text { excluded =7 }\end{array}$ \\
\hline $\begin{array}{l}\text { Low dose IV Ketamine as } \\
\text { interventional agent } \\
\text { started at cervical } \\
\text { dilatation of } 3 \text { cms during } \\
\text { active labour in all cases. }\end{array}$ & $\begin{array}{l}\text { During administration of interventional } \\
\text { drug the maternal pulse rate, blood } \\
\text { pressure, respiratory rate and lobour } \\
\text { pain as well as foetal Apgar score was } \\
\text { assessed and noted apart from progress } \\
\text { of labour in all cases and results } \\
\text { analyzed. }\end{array}$ \\
\hline \multicolumn{2}{|c|}{ Interventional Study-Flow chart } \\
\hline \multicolumn{2}{|c|}{} \\
\hline \multicolumn{2}{|c|}{}
\end{tabular}

The $500 \mathrm{~mL}$ IV dextrose containing calculated dose $11 \mathrm{mg}$ / $\mathrm{Kg}$ ) of ketamine hydrochloride was prepared and administered at rate of 50 drops per minute using infusion pump continuously in every case at cervical dilatation of 3 centimetres and having good uterine contractions. Every case received the drug till delivery of fetus. In all cases pulse rate, blood pressure and respiratory rate of mother was noted. Thereafter, vitals and decent of presenting fetal part was reassessed every hourly in $1^{\text {st }}$ stage and every 15 minutes in $2^{\text {nd }}$ stage of labour. Under strict aseptic precaution progress of labour was noted by pelvic assessment regarding decent of presenting part and cervical dilatation every two hourly and at rupture of membranes. The magnitude of pain during active labour (VAS score) and actual dose of IV ketamine delivered was noted in every case. VAS is a psychometric response scale 
that measures attitude or expression of individual for pain response on a scale of $0-10$ and can be used for assessment of labour pain during delivery in every case. Apgar scores at 1 and 5 minutes were noted in every new-born. All cases received injection Midazolam $2 \mathrm{mg}$ IV soon after the delivery of baby. After 4 hours of completion of labour in all cases, the sensation of pain after start of the IV drug and during labour was interrogated as to whether it was not felt at all, or decreased, or remained unchanged throughout, and accordingly the status of pain relief was noted as either complete, mild to moderate, or no relief and correlated with score of VAS 5 (Table 1).

\begin{tabular}{|cc|}
\hline VAS Score & Grades of Pain Relief \\
0 & No pain \\
$1-3$ & Mild \\
$4-7$ & Moderate \\
$8-10$ & Severe \\
\hline Table 1. VAS and Relief from Pain $^{5}$ \\
\hline
\end{tabular}

The emergence reactions of ketamine were looked for in every case within first hour and up to $4-6$ hours of stopping the drip.

\section{Statistical Analysis}

Unpaired t test was used to assess level of significance of VAS scores and Apgar score using SPSS InStat 3.06.

\section{RESULTS}

Amongst 73 cases, there were 39 primi and 34 multi gravida that underwent spontaneous vaginal delivery after receiving low dose of ketamine for painless labour. Of these 73 cases the age ranged between 19 to 35 years with mean $25.78 \pm 4.57$ years and having mean weight of $53.6 \pm 2.87 \mathrm{Kg}$. The duration of labour in 73 cases who delivered spontaneously (normal) was less than 6 hrs. in 8 cases, 6 - 8 hrs. in 48 and 8 - 10 hrs. in 17 with mean time required was $7.4 \pm 1.6$ hours. Out of these 73 in $8(11 \%)$ cases had increase uterine contractions and precipitate labour within less than 6 hours while in remaining 65 (89\%) there was no change in uterine contractions. Amongst 73 cases, in $61(84 \%)$ and 12 (16\%) cases the placenta was delivered within 10 to 15 and 15 to 20 minutes respectively.

The relief from labour pain was found in majority of the 61 $(83.57 \%)$ cases $(p<0.0001)$. And in $12(16.43 \%)$ cases it was moderate and severe (Table 2). Amongst all women the mean VAS of pain relief was $1.21 \pm 2.26$ (Table 3 ).

\begin{tabular}{|cc|}
\hline VAS (Visual Analogue Score) & Number of Cases \\
\hline 0 (No Pain) & $51(70 \%)$ \\
$1-3$ (Mild Pain) & $10(14 \%)$ \\
$4-7$ ( Moderate Pain) & $9(12 \%)$ \\
$8-10$ (Severe Pain) & $3(4 \%)$ \\
\hline Table 2. Grading of VAS and Pain Relief \\
\hline
\end{tabular}

\begin{tabular}{|lccc|}
\hline $\begin{array}{c}\text { VAS and Apgar } \\
\text { Scores }\end{array}$ & Mean $\pm \mathrm{SD}$ & 't' test & $\mathrm{p}$ value \\
VAS $(\mathrm{n}=73)$ & $1.21 \pm 2.26$ & 4.78 & $<0.0001^{*}$ \\
$\begin{array}{c}\text { One-minute Apgar (n } \\
=75)\end{array}$ & $8.375 \pm 1.4$ & 4.893 & $<0.0001^{*}$ \\
$\begin{array}{c}\text { Five minutes Apgar } \\
(\mathrm{n}=75)\end{array}$ & $9.35 \pm 1.104$ & & \\
\hline Table 3. Analysis-VAS in Mothers and Apgar Score in New-Born Babies \\
\hline "Significant
\end{tabular}

In this study the pulse rate increased in 26 (36\%) cases by 10 - 15 beats / minutes while in 47 (64\%) cases it remained unchanged. Also, the systolic and diastolic blood pressure increased in 22 (30\%) cases by $10-20 \mathrm{~mm} \mathrm{Hg}$ while in 51 (70 $\%)$ cases there was no significant change. Also, the respiratory rate increased in $43(59 \%)$ cases while in 30 (41\%) cases no change was seen. FHS (Fetal Heart Sounds) increased in 35 (48 $\%$ ) cases by $10-15$ beat per min while in 5 (7\%) cases it reduced to 80 - 90 beat per minute and in $33(45 \%)$ there was no change.

In all 75 babies did deliver spontaneously including 2 twin babies with mean Apgar scores at 1 and 5 minutes $8.735 \pm 1.4$ and $9.35 \pm 1.104$ respectively (Table 3 ). Apgar score at $1 \& 5$ minute in $69(92 \%)$ babies was significantly normal i.e. above 7 ( $<<0.0001)$ by using unpaired t test. $6(8 \%)$ babies showed Apgar score fairly low i.e. between 6 to 4 . No baby had critically low Apgar score $<3$.

Emergence reaction like hallucination was seen in 6 (8\%), delirium in $2(3 \%)$, restlessness in $5(7 \%)$, drowsiness in 16 (22\%), vomiting in $5(7 \%)$, nausea in $3(4 \%)$, head ache 2 (3 $\%$ ) and giddiness $11(15 \%)$, both nausea and headache in 4 (5 $\%)$, hallucination along with delirium in 3 (4\%) while remaining all were without any complications.

\section{DISCUSSION}

In the present study, ketamine in a dose of $1 \mathrm{mg} / \mathrm{Kg}$ in 500 $\mathrm{mL}$ of $5 \%$ dextrose at a rate of 50 drops per minute was infused continuously using infusion pump till delivery of fetus. Due to reduction of pain during labour by ketamine there was less maternal exhaustion and the patients remained cooperative throughout. Also, as a result of oxytocic effect there was increase in uterine contractions and cervical dilatation resulting in shortening of first stage of labour. In present study there was minimal effect of ketamine on uterine contraction up to $2^{\text {nd }}$ stage of labour in $89 \%$ cases while in $84 \%$ cases the duration of $3^{\text {rd }}$ stage was reduced which correlates with studies done by Chodoff \& Stella et al, ${ }^{6}$ Sharma et al,7 Sarkar \& Sahu et $\mathrm{al}^{8}{ }^{8}$ Dftary and Desai et $\mathrm{al}^{9}$ and Krishna Jagatia et $\mathrm{al}^{10}$ who noted that progress of labour was not hampered and $3^{\text {rd }}$ stage of labour was characterized by prompt uterine contractions with rapid expulsion of placenta. In present study, out of 73 cases significant complete pain relief in 61 $(83.56 \%)$ cases was in accordance with studies by Sam Joel et $\mathrm{al}^{2}$ Dftary and Desai et $\mathrm{al}^{8}$ where in it was 60 and $70 \%$ respectively. Similarly, increase in pulse rate in 26 (36\%) cases by $10-15$ beats / minutes $(p=0.131)$ and increase in both systolic and diastolic blood pressure by $10-20 \mathrm{~mm} \mathrm{Hg}$ in $22(30 \%)$ cases was insignificant $(\mathrm{p}=0.103)$. And this was correlating with studies done by Krishna Jagatia et al, ${ }^{10}$ Sarkar \& Sahu et $\mathrm{al}^{8}$ and Cheesman, K., Makinde et al ${ }^{11}$, Sam Joel, A.S. Joselyn et $\mathrm{al}^{2}$ who noted no serious maternal complication except transient \& mild rise in B.P. and pulse rate which reverted to normal after stoppage of infusion. The Apgar score of $7-10$ at 1 and 5 minutes was significantly normal in 69 (92 $\%)$ babies ( $<<0.0001)$. In $6(8 \%)$ babies Apgar was $4-6$ at 5 minutes consequent to having meconium aspiration. Also, the studies by Jagatia et al, ${ }^{10}$ Sharma and Parekh et al ${ }^{7}$. Sarkar and Sahu et $\mathrm{al}^{7}$ and Singh $\mathrm{KN}^{12}$ have found no effect of ketamine on Apgar score at 1 and 5 minutes. 
Emergence reaction like hallucination was seen in $6(8 \%)$, delirium in 2 (3\%), restlessness in 5 (7\%), drowsy in $16(22$ $\%)$, vomiting in 5 (7\%), nausea in $3(4 \%)$, head ache - $2(3 \%)$ and giddiness - $11(15 \%)$, both nausea and headache in 4 (5 $\%)$, hallucination along with delirium in 3 (4\%) which is similar with the studies done by Ayanade 0 et al,13 Sharma et $\mathrm{al}^{7}$ and Sarkar \& Sahu et $\mathrm{al}^{8}$ which also have found no serious maternal complication.

\section{CONCLUSIONS}

Low dose ketamine in a drip for painless labour caused neither any change in uterine contractions nor an untoward effect on cervical dilatation and foetal health, and yet it provided relief from labour pain during active labour in majority of cases. The pulse rate and blood pressure in $64 \%$ and $70 \%$ cases remained unchanged even though $59 \%$ cases had transient increase in the respiratory rate. Normal Apgar score $(>7)$ was found in the majority (92\%) of new-borns. Emergence reactions lasting for less than 4 hours were found in 57 (78\%) cases. Slow intravenous infusion of low dose ketamine hydrochloride was significantly effective as well as easy to administer and monitor, besides being cost effective, and without significant maternal and fetal complications when used for painless labour in this study. Therefore, this modality of providing painless labour should be preferred in cases opting for it; however, meticulous monitoring of progress of labour and foetal health remains mandatory.

Data sharing statement provided by the authors is available with the full text of this article at jemds.com.

Financial or other competing interests: None.

Disclosure forms provided by the authors are available with the full text of this article at jemds.com.

Ethical clearance was obtained from Institutional Ethics Committee vide letter No. KIMSDU/IEC/03/2019 dated 09/07/2019.

\section{REFERENCES}

[1] Dowswell T, Bedwell C, Lavender T, et al. Transcutaneous electrical nerve stimulation (TENS) for pain management in labour. Cochrane Database Syst Rev 2015: p. 1-6.

[2] Joel S, Joselyn A, Cherian VT, et al. Low - dose ketamine infusion for labour analgesia: a double - blind, randomized, placebo controlled clinical trial. Saudi J Anaesth 2014;8(1):6-10.

[3] Kilpatrick SJ, Laros RK. Characteristics of normal labour. Obstet Gynecol 1989;74(1):85-7.

[4] Panzer O, Moitra V, Sladen RN. Pharmacology of sedativeanalgesic agents: dexmedetomidine, remifentanil, ketamine, volatile anaesthetics and the role of peripheral mu antagonists. Crit Care Clin 2009;25(3):451-69.

[5] Breivik H, Borchgrevink PC. Assessment of pain. Br J Anaesth 2008;101(1):17-24.

[6] Chodoff P, Stella JG. Use of CI-581-a phen- cyclidine derivative for obstetric anaesthesia. Anaesth \& Analg 1966;45(5):527-30.

[7] Sharma S, Parekh P. Intravenous ketamine for painless vaginal delivery. J Obstet Gynaecol India 1993;43:738-42.

[8] Sarkar P, Sahu SP. Ketamine hydrochloride for painless labour. Indian J Anaesth 1992;40:120-3.

[9] Dftary SN, Desai SV, Thanawala U, et al. Programmed labour - indegenous protocol to optimize labour outcome. South Asian Federation Obstet Gynecol 2009;1(1):61-4.

[10] Jagatia K, Mehta J, Patel N. Low dose ketamine for painless labour: a comparative study of 100 patients. Int J Med Sci Public Health 2013;2(3):707-11.

[11] Cheesman K, Makinde S, Bird G. Pressure ulcers in parturients. Int J Obstet Anaesth 2010;19(1):121-2.

[12] Singh KN. A study to assess efficacy of lower dose ketamine in labour analgesia and its effect on maternal and perinatal outcome. Int J Reprod Contracept Obstet Gynecol 2018;7(11):4521-4.

[13] Ayangade 0. Microadministration of ketamine during labour and delivery of Nigerian women. Int J Gynaecol Obstet 1979;17(1):88-90. 